Research Article

\title{
Spectrophotometric Determination of $p$-Nitrophenol under ENP Interference
}

\author{
Hui Xia, ${ }^{1}$ Wenjing Zhang $\mathbb{D}^{2}{ }^{2}$ Zhijie Yang, ${ }^{3}$ Zhenxue Dai, ${ }^{3}$ and Yuesuo Yang $\mathbb{D}^{1,3}$ \\ ${ }^{1}$ Key Lab of Eco-Restoration of Regional Contaminated Environment (Shenyang University), Ministry of Education, \\ Shenyang 110044, China \\ ${ }^{2}$ Green Catalysis Center and College of Chemistry, Zhengzhou University, Zhengzhou 450001, China \\ ${ }^{3}$ Key Lab of Groundwater and Environment (Jilin University), Ministry of Education, Changchun 130021, China
}

Correspondence should be addressed to Wenjing Zhang; zhangwj@zzu.edu.cn and Yuesuo Yang; yangyuesuo@jlu.edu.cn

Received 17 October 2020; Revised 8 December 2020; Accepted 15 December 2020; Published 7 January 2021

Academic Editor: Eduardo Dellacassa

Copyright (c) 2021 Hui Xia et al. This is an open access article distributed under the Creative Commons Attribution License, which permits unrestricted use, distribution, and reproduction in any medium, provided the original work is properly cited.

\begin{abstract}
Engineered nanoparticles (ENPs) have been widely developed in various fields in recent years, resulting in an increasing occurrence of nanoparticles in the natural environment. However, the tiny substances have created unexpected confusion in environmental sample testing due to the negative nanoeffect of ENPs. In this paper, a novel technique of spectrophotometric determination of $p$-nitrophenol (PNP) was developed under the interfering impact of nano- $\mathrm{Fe}(\mathrm{OH})_{3}$, widely distributed in the natural environment as a typical example of ENPs. Because of the strong absorption at the two characteristic peaks of PNP, namely, $317 \mathrm{~nm}$ and $400 \mathrm{~nm}$, nano- $\mathrm{Fe}(\mathrm{OH})_{3}$ interfered with the colorimetric determination of PNP. Thus, the developed testing method, with $\mathrm{HCl}$ acidification at $60^{\circ} \mathrm{C}$ and ascorbic acid (AA) masking $\mathrm{FeCl}_{3}$, was proposed and successfully realized the accurate determination of PNP in water samples by ultraviolet spectrophotometry with $317 \mathrm{~nm}$ as the absorption wavelength. The final colorimetric system of $5 \% \mathrm{HCl}, 10 \% \mathrm{CH}_{3} \mathrm{OH}$, and $1 \%$ ascorbic acid was confirmed by optimized batch experiments, and the optimum condition of acidification pretreatment was heating at $60^{\circ} \mathrm{C}$ for $20 \mathrm{~min}$. Further results demonstrated that the proposed novel method had good accuracy and reproducibility even in high-salinity natural water bodies such as groundwater and surface water. The testing technique presented in this paper provided an interesting and useful tool for problem solving of PNP surveys under ENPs' interference and practically supported water quality assessment for a better environment.
\end{abstract}

\section{Introduction}

p-nitrophenol (PNP), a class of highly toxic and environmental persistent organic pollutants (POPs), is not easily biodegradable or naturally photolyzed; it accumulates and causes long-term damage to the environment, so PNP is one of the most frequently detected organic pollutants $[1,2]$. In view of the environmental toxicity and chemical inactivity, PNP has been often used as a typical representative of POPs, and more and more environmental workers have begun to carry out environmental engineering treatment and laboratory research work on PNP. However, before carrying out the related work, the first key issue was how to find a simple, economical, and accurate test method. At present, the relatively mature test methods for PNP included UV-vis spectrophotometry [3, 4], highperformance liquid chromatography $[5,6]$, gas chromatography-mass spectrometry $[7,8]$, and electrochemical assessment [9-11]. Among them, UV-vis spectrophotometry has the advantages of simple operation, rapidity, low labor intensity, and high analysis efficiency. More importantly, the instrument used in the method was cheap, and almost all chemical laboratories were equipped to use it. However, it should be noted that there are more and more engineered nanoparticles (ENPs) in environmental water samples due to the rise of nanotechnology, and the nanosubstances bring unexpected trouble to the traditional analysis and testing of POPs. For example, iron-based ENPs will interfere with the UV-vis spectrophotometric determination of PNP. 
Actually, nanotechnology has revolutionized various research fields, andENPs have found broader application in environmental remediation [12-14], new energy [15], biomedicine [16], daily consumer goods [17, 18], agriculture [19], etc., due to their extensive potentiality and versatility in the past decade [20]. As shown in Figure 1, our research group [21-23] found that these emerging ENPs enter into the groundwater and surface water bodies by atmospheric sedimentation, surface runoff, underground infiltration, etc. However, the ENPs would be adsorbed in environmental media or comigrate with environmental pollutants due to their unique nanoproperties, such as huge specific surface area, strong adsorption, catalysis, chelating ability, etc. $[24,25]$. As a result, a new type of stable nanocolloid was formed by the ENPs in groundwater and surface water systems and stayed in the environment for a long time. Unfortunately, the nanocolloid would change the light paths, which might limit the application of analytical methods based on spectral theory. So, it was indispensable and of great significance to study the ENPs' influence on the accuracy and stability of the analysis results when carrying out pollutant testing work in the groundwater and surface water bodies.

For the past couple of years, environmental remediation technology based on metallic iron ENPs has been investigated as a new tool for water and soil treatment and has gradually been accepted and commercialized in many countries due to its effectiveness in the removal of pollutants as well as the low cost of production [26, 27]. For example, the pollution remediation agent nano- $\mathrm{Fe}^{0}$ has the advantages of high efficiency, low cost, low toxicity, etc., and has received extensive attention in the in situ remediation of heavy metal and organic pollutants in soil [28]. $\mathrm{Nano}-\mathrm{Fe}_{3} \mathrm{O}_{4}$, as a heterogeneous catalyst, was evaluated to activate $\mathrm{Na}_{2} \mathrm{~S}_{2} \mathrm{O}_{8}$, which was proven to be an efficient and promising agent for the treatment of leachate biochemical effluent [14]. Bagbi and coworkers [29] successfully synthesized L-cysteinefunctionalized $\mathrm{Fe}_{3} \mathrm{O}_{4}$ nanoparticles that could be reused for lead and chromium adsorption removal. He and his coworkers [30] reported nanoscale zero-valency iron/nickel supported on zeolite for the simultaneous removal of nitrate and phosphate from an aqueous solution. Chen and coworkers [31] concluded that nano-FeS could not only remove redox-sensitive pollutants by a chemical redox reaction, but could also treat pollutants by chemical adsorption due to its larger specific surface area and higher reactivity than macro-FeS.

In the process of water treatment, $\mathrm{Fe}(\mathrm{OH})_{3}$ nanoparticles gradually evolve from the above iron-based ENPs and remain in the aqueous solution for a long time in the form of brown-red $\mathrm{Fe}(\mathrm{OH})_{3}$ colloids. The $\mathrm{Fe}(\mathrm{OH})_{3}$ colloid has strong absorption at the characteristic absorption peaks of PNP $(317 \mathrm{~nm}$ and $400 \mathrm{~nm}$ ), which interferes with the test results of UV-Vis spectrophotometry. In this paper, an improved technique for the spectrophotometric determination of PNP, as a typical POPs, is developed under interfering conditions of nano- $\mathrm{Fe}(\mathrm{OH})_{3}$, as a typical example of ENPs in a natural aqueous environment. $\mathrm{HCl}$ acidification at $60^{\circ} \mathrm{C}$ and ascorbic acid (AA) masking of $\mathrm{FeCl}_{3}$ were conducted in order to eliminate the negative effect of $\mathrm{Fe}(\mathrm{OH})_{3}$ on the spectrophotometric determination of PNP. The influencing factors such as heating time, $\mathrm{HCl}$ dosage, temperature, and common anions and cations were optimized through batch experiments. Finally, the accuracy of the improved testing method was verified by standard experiments, and the precision was investigated in several repeated experiments. This work provided robust results to support the environmental scientists' further investigations into both the treatment of POPs and the cotransport of ENPs and organic contaminants.

\section{Materials and Methods}

2.1. Chemicals and Reagents. $p$-nitrophenol $\left(\mathrm{C}_{6} \mathrm{H}_{5} \mathrm{NO}_{3}\right.$, Cas: 100-02-7, Macklin Biochemical Technology Co., Ltd., Shanghai, China, the physical and chemical properties are shown in Table 1); hydrochloric acid ( $\mathrm{HCl}$, Beijing Chemical Plant Co., Ltd., Beijing, China); methanol $\left(\mathrm{CH}_{3} \mathrm{OH}\right.$, highperformance liquid chromatography grade, Thermo Fisher Scientific, Waltham, USA); sodium bicarbonate $\left(\mathrm{NaHCO}_{3}\right.$, Sigma Aldrich (Shanghai) Trading Co., Ltd., Shanghai, China); ascorbic acid $\left(\mathrm{C}_{6} \mathrm{H}_{8} \mathrm{O}_{6}\right.$, Sinopharm Chemical Reagent Co., Ltd., Shanghai, China); calcium chloride $\left(\mathrm{CaCl}_{2}\right)$, manganese sulfate $\left(\mathrm{MnSO}_{4} \cdot \mathrm{H}_{2} \mathrm{O}\right)$, potassium nitrate $\left(\mathrm{KNO}_{3}\right)$, ferric chloride $\left(\mathrm{FeCl}_{3} \cdot 6 \mathrm{H}_{2} \mathrm{O}\right)$, magnesium sulfate $\left(\mathrm{MgSO}_{4} \cdot 7 \mathrm{H}_{2} \mathrm{O}\right)$, and potassium chloride $(\mathrm{KCl})$ were purchased from Tianjin Bodi Chemical Co., Ltd., Tianjin, China. All the reagents involved in this article were of analytical grade or higher. All solutions were prepared with ultrapure water from a pure water treatment process $(\geq 18 \mathrm{M} \Omega \cdot \mathrm{cm}$, Milli-Q Advantage A10, Millibo (Shanghai) Trading Co., Ltd., Shanghai, China).

2.2. Preparation of Experimental Solutions. Stock solutions of PNP (1.000 g/L), $\mathrm{NaHCO}_{3}(3.440 \mathrm{~g} / \mathrm{L}), \mathrm{MgSO}_{4}(5.000 \mathrm{~g} / \mathrm{L})$, $\mathrm{CaCl}_{2}(2.774 \mathrm{~g} / \mathrm{L}), \mathrm{KCl}(0.956 \mathrm{~g} / \mathrm{L}), \mathrm{MnSO}_{4}(1.388 \mathrm{~g} / \mathrm{L})$, and $\mathrm{KNO}_{3}(1.628 \mathrm{~g} / \mathrm{L})$ were prepared in ultrapure water in order to match the salt content in natural water. The corresponding working solutions were obtained by diluting stock solutions daily in ultrapure water. The PNP standard solutions of $0.00 \mathrm{mg} / \mathrm{L}, 4.00 \mathrm{mg} / \mathrm{L}, \quad 8.00 \mathrm{mg} / \mathrm{L}, 12.0 \mathrm{mg} / \mathrm{L}$, $16.0 \mathrm{mg} / \mathrm{L}$, and $20.0 \mathrm{mg} / \mathrm{L}$ were diluted step by step with the PNP stock solution. It should be noted that the six PNP standard solutions all contained $10 \% \mathrm{CH}_{3} \mathrm{OH}, 5 \% \mathrm{HCl}$, and $1 \mathrm{~g} / \mathrm{L}$ ascorbic acid. Afterwards, the absorbance of PNP standard solutions was determined at $317 \mathrm{~nm}$, which was the unique characteristic UV wavelength of PNP. The PNP standard curve was drawn with the concentration as the abscissa and absorbance as the ordinate, and the linear regression equation was obtained by fitting, as shown in Figure 2(a). It was concluded that the PNP standard curve was linear in the range of $0.00-20.0 \mathrm{mg} / \mathrm{L}$, and its correlation coefficient, $R^{2}$, was above 0.999 .

The nano- $\mathrm{Fe}(\mathrm{OH})_{3}$ solution was prepared by extended hydrolysis of $\mathrm{Fe}^{3+}$. In detail, $0.0776 \mathrm{~g} \mathrm{FeCl}_{3} \cdot 6 \mathrm{H}_{2} \mathrm{O}$ was dissolved in $250 \mathrm{~mL}$ ultrapure water and hydrolyzed naturally at room temperature for more than four days. Before using the 


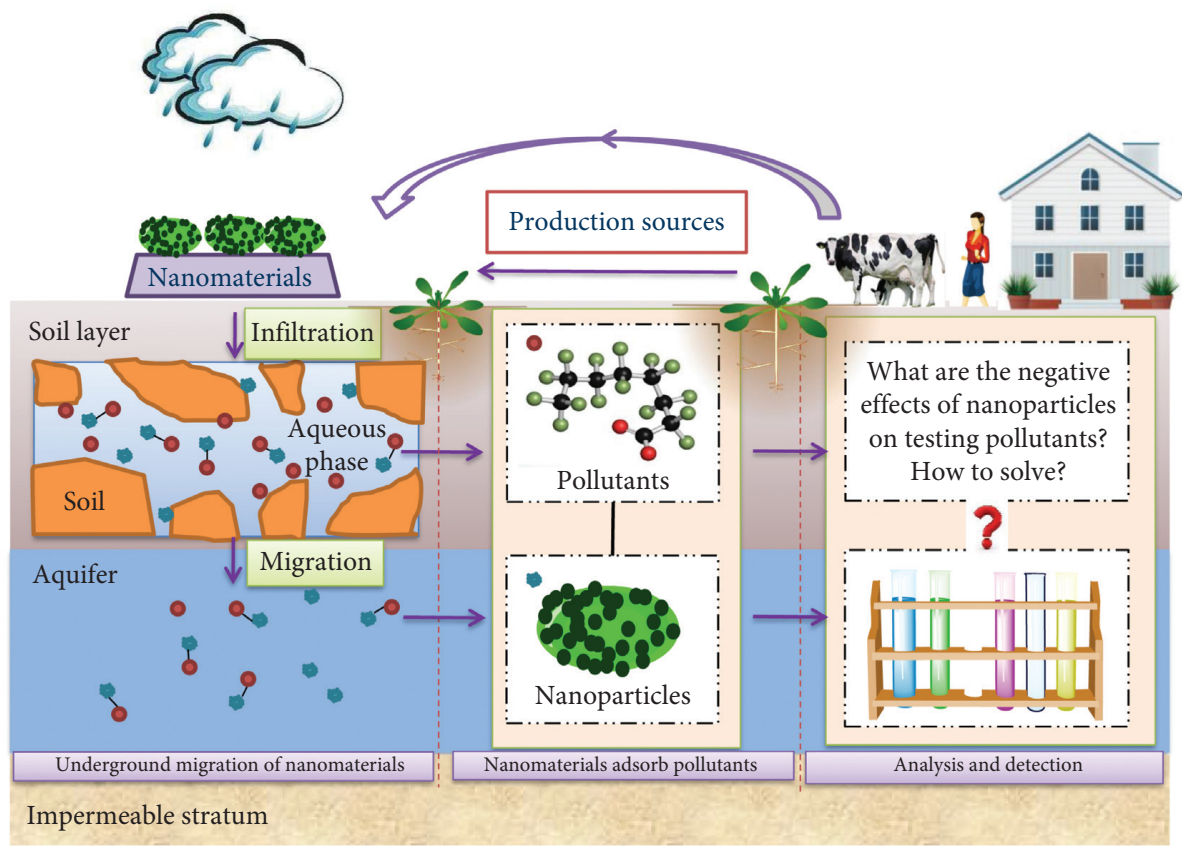

FIGURE 1: Significance of testing in the comigration of ENPs and environmental pollutants.

Table 1: The physical and chemical properties of $p$-nitrophenol [32].

\begin{tabular}{|c|c|c|c|}
\hline Parameter & PNP & Parameter & PNP \\
\hline Molecular formula & $\mathrm{C}_{6} \mathrm{H}_{5} \mathrm{NO}_{3}$ & Molar mass & $139.11 \mathrm{~g} / \mathrm{mol}$ \\
\hline $\mathrm{pKa}$ & $7.15\left(25^{\circ} \mathrm{C}\right)$ & Water solubility & $1.6 \mathrm{~g} / \mathrm{L}\left(25^{\circ} \mathrm{C}\right)$ \\
\hline Melting point & $113-114^{\circ} \mathrm{C}$ & Boiling point & $279{ }^{\circ} \mathrm{C}$ \\
\hline $\mathrm{LD}_{50}$ & $250 \mathrm{mg} / \mathrm{kg}$ (rats, orally) & Octanol/water partition coefficient & 1.91 \\
\hline \multicolumn{4}{|c|}{ Molecular structure in acid solution (colorless) } \\
\hline Molecular struc & e solution (yellow) & & \\
\hline
\end{tabular}

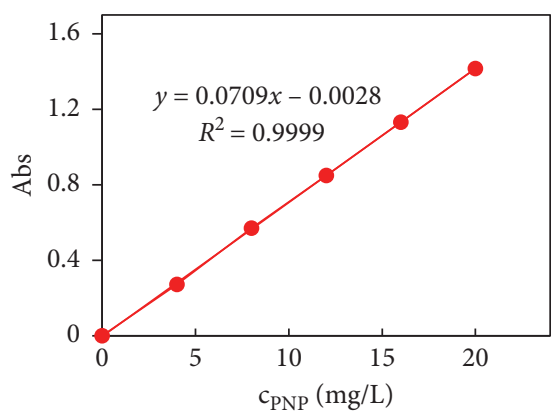

(a)

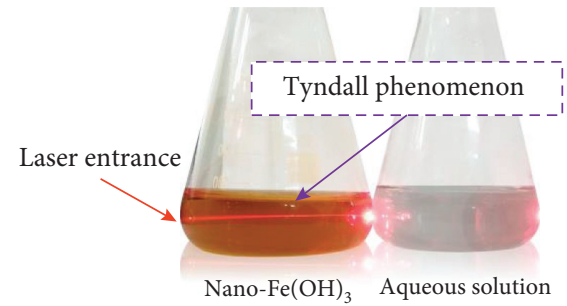

(b)

Figure 2: (a) PNP standard curve. (b) Tyndall phenomenon of the nano-Fe $(\mathrm{OH})_{3}$ solution.

solution, the particle size and $\zeta$ potential of the nano- $\mathrm{Fe}(\mathrm{OH})_{3}$ solution were measured by a Particle Sizer and Zeta Potential Analyzer (Nano-ZS, Malvern, UK), as shown in Table 2. The average particle size of $\mathrm{Fe}(\mathrm{OH})_{3}$ was $39.2 \mathrm{~nm}$, which proved that the solution was a nanocolloid. The average $\zeta$ potential was $35.3 \mathrm{mV}$, which implied that the nano- $\mathrm{Fe}(\mathrm{OH})_{3}$ system was very stable after extended hydrolysis $[33,34]$. In order to further verify the existence of the colloid, a simple Tyndall 
TABle 2: The properties of the nano- $\mathrm{Fe}(\mathrm{OH})_{3}$ solution.

\begin{tabular}{|c|c|c|c|c|c|}
\hline Reagents & Times & Particle size (d.nm) & Average (d.nm) & Zeta potential $(\mathrm{mV})$ & Average $(\mathrm{mV})$ \\
\hline \multirow{3}{*}{ Nano- $\mathrm{Fe}(\mathrm{OH})_{3}$} & 1 & 38.80 & \multirow{3}{*}{39.2} & 31.7 & \multirow{3}{*}{35.4} \\
\hline & 2 & 38.41 & & 37.4 & \\
\hline & 3 & 40.54 & & 37.2 & \\
\hline
\end{tabular}

experiment was carried out, as shown in Figure 2(b). A bright red "light channel," which was the Tyndall phenomenon, was obviously observed when a laser was irradiated from the side of the solution. Therefore, it was proven that the nano$\mathrm{Fe}(\mathrm{OH})_{3}$, obtained by four-day natural hydrolysis, was suitable for the follow-up study of nanoparticles interfering with PNP tests.

\subsection{Improved Analytical Methods for Assessing PNP in the} Presence of Nano- $\mathrm{Fe}(\mathrm{OH})_{3}$. It was found that the existence of engineered nanoparticles, such as nano- $\mathrm{Fe}(\mathrm{OH})_{3}$, could lead to inaccurate spectrophotometric results because they formed stable nanomicelles in solution. It is universally known that the surface structure of colloidal particles could be broken, and their stability could be destroyed by adding electrolytes or heating. In this context, $5 \% \mathrm{HCl}$ was added to the colorimetric system and heated at $60^{\circ} \mathrm{C}$ for $20 \mathrm{~min}$ in order to dispel the negative effect of nano- $\mathrm{Fe}(\mathrm{OH})_{3}$. The preparation and purification procedures were as follows.

First, $1-5 \mathrm{~mL}$ of $40 \mathrm{mg} / \mathrm{L}$ PNP standard solution was sampled and injected into a $10 \mathrm{~mL}$ colorimetric tube, and $1.00 \mathrm{~mL} \mathrm{CH} \mathrm{CH}_{3} \mathrm{OH}, 2.00 \mathrm{~mL}$ nano- $\mathrm{Fe}(\mathrm{OH})_{3}$ solution, and $1.00 \mathrm{~mL} \mathrm{HCl}(50 \%, \mathrm{v} / \mathrm{v})$ were added in turn. An additional $2 \mathrm{~mL}$ of the corresponding ions' stock solutions was added for the experiment on coexisting ion interference. Afterwards, the samples were slightly warmed at $60{ }^{\circ} \mathrm{C}$ for $20 \mathrm{~min}$, and then $1 \mathrm{~mL}$ of ascorbic acid solution $(5 \mathrm{~g} / \mathrm{L})$ was added after cooling. Finally, the PNP was quantitatively analyzed at a wavelength of $317 \mathrm{~nm}$, which was the characteristic UV peak under acidic conditions, as revealed by UV-visible spectrophotometry (Hitachi U-2910, Hitachi Ltd., Tokyo, Japan). The abovementioned procedures and experimental phenomena are shown in Figure 3.

\section{Results and Discussion}

3.1. Selection of Analytical Spectral Lines. It can be seen from Figure 4(b) that $p$-nitrophenol had only one UV absorption peak of $317 \mathrm{~nm}$ under strongly acidic conditions (see the green line) and the solution was colorless, while there was only one absorption peak at $400 \mathrm{~nm}$ under strongly alkaline conditions (see the red line), and the solution was yellow. The two characteristic peaks coexist in a pure aqueous solution (see the blue line), and the color of the solution becomes lighter. At the same concentration, the absorbance of $400 \mathrm{~nm}$ in strong alkalinity was higher than that at $317 \mathrm{~nm}$ under strong acidity, which indicated that the sensitivity of colorimetry using $400 \mathrm{~nm}$ as a characteristic wavelength was higher. However, there were many heavy metals, such as $\mathrm{Ca}$, $\mathrm{Mg}, \mathrm{Fe}$, etc., in natural water $[35,36]$. Actually, these heavy metals would produce microscopic particles in an alkaline solution, which interfered with the accuracy of the determination. For example, the Fe ion, even at low concentrations, formed a colloid under alkaline conditions, which interfered with the results of the colorimetric determination (see Figure 4(a)). Because these metals are soluble under acidic conditions, $317 \mathrm{~nm}$, which was the characteristic peak in acidic water, was selected as the analytical wavelength of PNP colorimetry in the actual testing work in order to avoid the interference of the metals.

3.2. Role of Methanol and Ascorbic Acid. As a common catalyst in the treatment of environmental pollution, metal Fe often catalyzed the production of high-energy hydroxyl radicals, which was used for the rapid and nonselective degradation of many organic pollutants [37-39]. Methanol was a classical quenching agent of hydroxyl radicals [40, 41], which could immediately interrupt the possible follow-up reaction of $\mathrm{OH}$ radicals, so as to obtain the accurate PNP concentration at the sampling time. Therefore, the addition of methanol during the testing process was to avoid the possible decomposition of PNP by hydroxyl radicals, which improved the application scope of the method.

In addition, it should be noted that the reagents, such as $\mathrm{CH}_{3} \mathrm{OH}, \mathrm{HCl}$, and $\mathrm{AA}$, had no UV absorption at $317 \mathrm{~nm}$ (see the blue, red, and green lines in Figure 4(a)), so it did not affect the results of the colorimetric determination of PNP.

A yellowish $\mathrm{FeCl}_{3}$ was regenerated from nano- $\mathrm{Fe}(\mathrm{OH})_{3}$ after acidizing with hydrochloric acid and heating pretreatment. Unfortunately, the $\mathrm{FeCl}_{3}$ would enhance the UV absorption at $317 \mathrm{~nm}$ and still interfered with the colorimetric determination of PNP. After consulting the literature, it was found that ascorbic acid was a common masking reagent for $\mathrm{Fe}(\mathrm{III})$ [42]. The valence state of Fe ion could be changed, i.e., $\mathrm{Fe}$ (III) could be reduced to $\mathrm{Fe}(\mathrm{II})$, due to the reducibility of ascorbic acid, as shown in Figure 5(a). As can be seen from Figure 5(b), after blank zero adjustment, the scanning peak shape between $280 \mathrm{~nm}$ and $500 \mathrm{~nm}$ of PNP with $\mathrm{Fe}(\mathrm{OH})_{3}$ after AA reduction treatment was basically the same as that of PNP under acidic conditions, and the absorbance at $317 \mathrm{~nm}$ was completely the same, which shows that the addition of ascorbic acid completely eliminated the $\mathrm{FeCl}_{3}$ interference. As a result, there was a prerequisite for the quantitative analysis of PNP.

3.3. Effect of Nano-Fe(OH) 3 and Coexisting Ions. In the groundwater and surface water, $\mathrm{K}^{+}, \mathrm{Na}^{+}, \mathrm{Ca}^{2+}, \mathrm{Mg}^{2+}, \mathrm{Fe}^{3+}$, $\mathrm{Mn}^{2+}, \mathrm{HCO}_{3}^{-}, \mathrm{SO}_{4}^{2-}, \mathrm{NO}_{3}^{-}$, and $\mathrm{Cl}^{-}$were the most common ions $[43,44]$. In order to study the interference of these ions with the improved method, the proportions were set according to Table 3, and standard addition batch experiments were carried out. According to the results in Table 3, when there was $\mathrm{K}^{+}, \mathrm{Na}^{+}, \mathrm{Ca}^{2+}, \mathrm{Mg}^{2+}, \mathrm{Fe}^{3+}, \mathrm{Mn}^{2+}, \mathrm{HCO}_{3}^{-}$, 


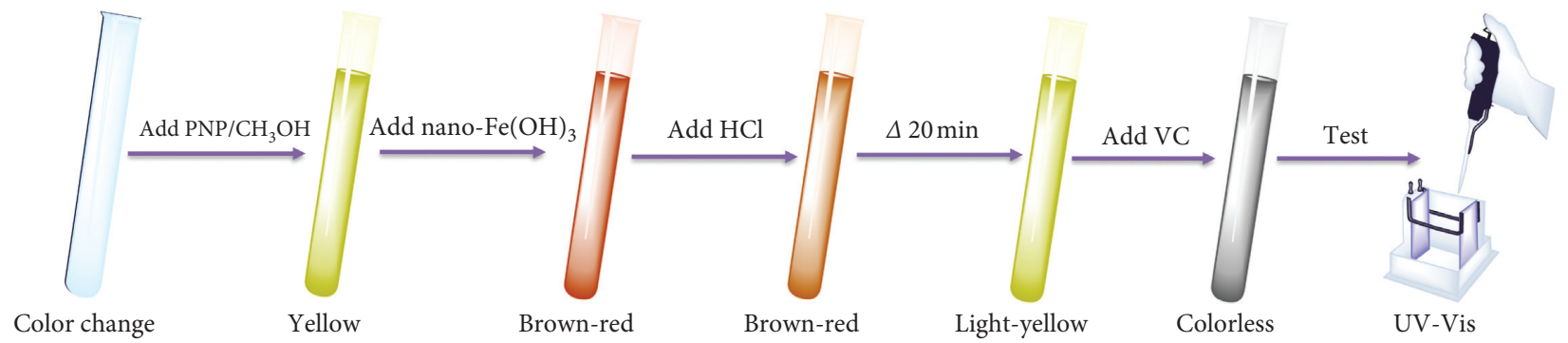

FIGURE 3: Experimental procedures and phenomena.

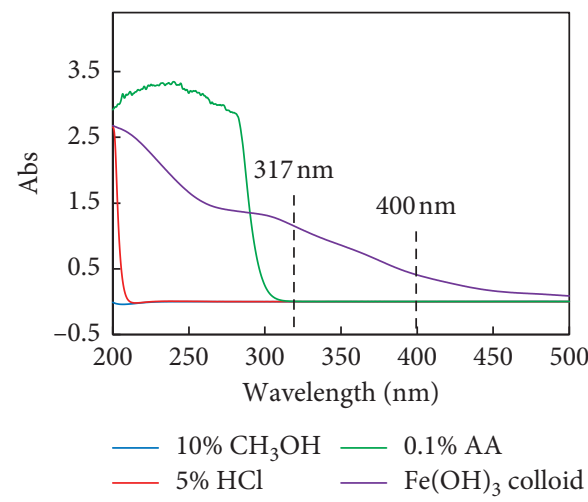

(a)

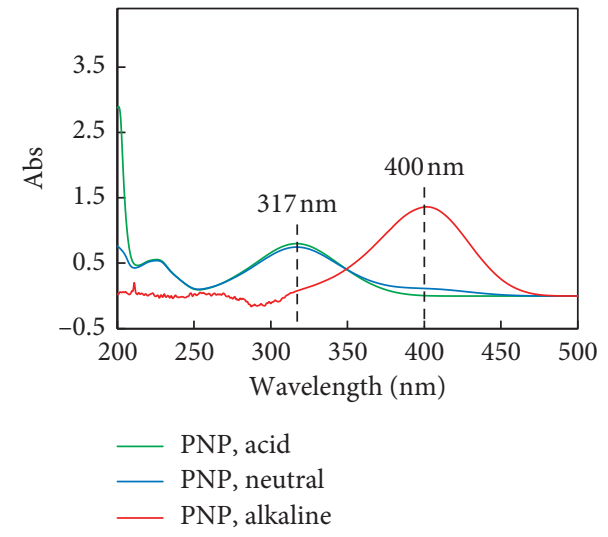

(b)

FIGURE 4: UV-Vis absorption spectra of (a) different reagents and (b) $20 \mathrm{mg} / \mathrm{L}$ PNP under different $\mathrm{pH}$.

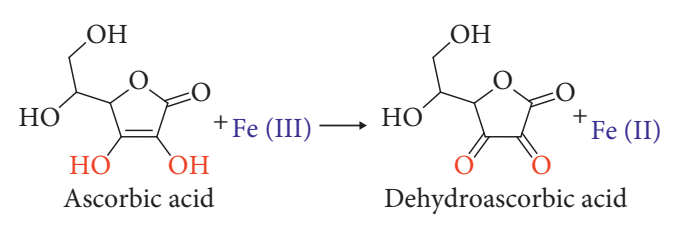

(a)

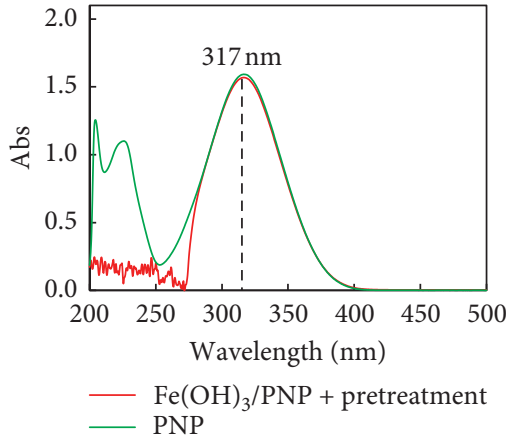

(b)

Figure 5: (a) Reduction of $\mathrm{Fe}(\mathrm{III})$ by AA. (b) Research on $\mathrm{Fe}(\mathrm{OH})_{3}$ interference elimination.

Table 3: The nano- $\mathrm{Fe}(\mathrm{OH})_{3}$ and coexisting ions interference test.

\begin{tabular}{|c|c|c|c|c|c|c|c|}
\hline Reagents & Nano- $\mathrm{Fe}(\mathrm{OH})_{3}$ & $\mathrm{NaHCO}_{3}$ & $\mathrm{MgSO}_{4}$ & $\mathrm{CaCl}_{2}$ & $\mathrm{KCl}$ & $\mathrm{MnSO}_{4}$ & $\mathrm{KNO}_{3}$ \\
\hline Cations addition $(\mathrm{mg} / \mathrm{L})$ & $10^{1}$ & 188 & 200 & 200 & 100 & 100 & 126 \\
\hline Anions addition $(\mathrm{mg} / \mathrm{L})$ & 3 & 500 & 800 & 355 & 182 & 177 & 200 \\
\hline PNP standard addition $(\mathrm{mg} / \mathrm{L})$ & 12 & 12 & 12 & 12 & 12 & 12 & 12 \\
\hline Measured value of PNP standard addition $(\mathrm{mg} / \mathrm{L})$ & 12.46 & 12.17 & 12.43 & 12.05 & 12.22 & 12.27 & 12.50 \\
\hline Standard recovery rate $(\%)$ & 103.9 & 101.4 & 103.6 & 100.4 & 101.8 & 102.3 & 104.2 \\
\hline
\end{tabular}

${ }^{1}$ The amount of nano- $\mathrm{Fe}(\mathrm{OH})_{3}$ added was calculated in terms of $\mathrm{Fe}$.

$\mathrm{SO}_{4}^{2-}, \mathrm{NO}_{3}^{-}$, and $\mathrm{Cl}^{-}$in the colorimetric system, the recoveries of all the experiments were in the range of $101-105 \%$, in line with our expectations indicates that the existence of these chemicals did not interfere with the results of PNP colorimetric determination. Moreover, when nano- $\mathrm{Fe}(\mathrm{OH})_{3}$ was added to the system, the recovery of PNP was $103.9 \%$, 


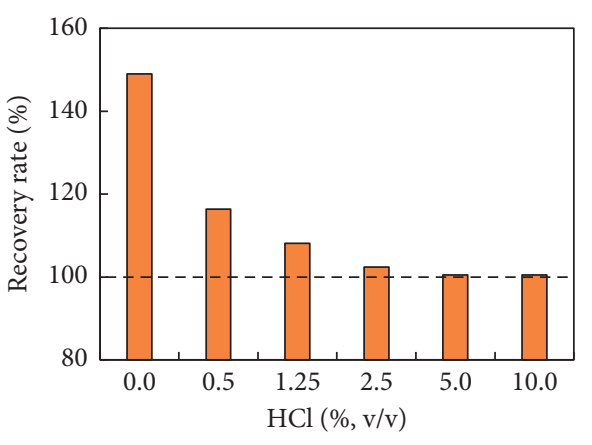

(a)

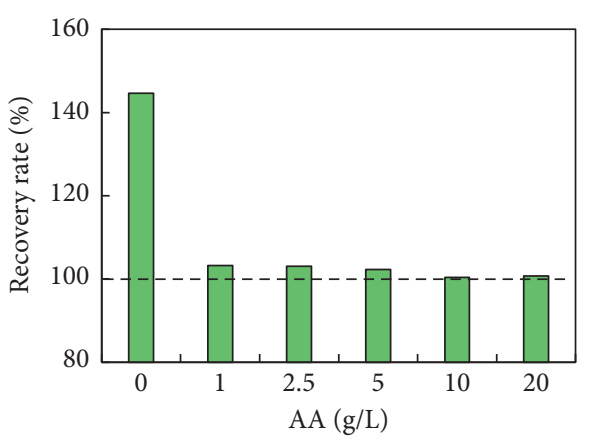

(b)

Figure 6: (a) Optimization of $\mathrm{HCl}$ dosage. (b) Optimization of AA dosage.

which indicated that the interference had been eliminated by the improved method.

3.4. Optimization of $\mathrm{HCl}$ and AA Dosage. There were two functions of $\mathrm{HCl}$ in the colorimetric system. On the one hand, the solution was acidic due to the addition of $\mathrm{HCl}$, so the ultraviolet absorption of PNP reached a maximum at $317 \mathrm{~nm}$, which allowed for effective quantitative colorimetry. On the other hand, the stability of nano- $\mathrm{Fe}(\mathrm{OH})_{3}$ was destroyed by $\mathrm{HCl}$ due to their neutralization reaction, thus achieving the purpose of eliminating nano- $\mathrm{Fe}(\mathrm{OH})_{3}$ interference. As shown in Figure 6(a), because the interference of $\mathrm{Fe}$ is not deducted, the recovery rate of PNP was 149\% without adding $\mathrm{HCl}$, which indicated that the PNP test result was incorrect, whereas the recovery rates were $116 \%, 108 \%$, $102 \%, 101 \%$, and $101 \%$, respectively, at $\mathrm{HCl}=0.5 \%, 1.25 \%$, $2.5 \%, 5 \%$, and $10 \%$. It was clear that the recovery rate was close to $100 \%$ when the amount of $\mathrm{HCl}$ was more than $5 \%$. Therefore, the reasonable use of $\mathrm{HCl}$ should be greater than $5 \%$ in the determination process.

As can be seen from Figure 6(b), the recovery rates were $145 \%, 103 \%, 103 \%, 102 \%, 100 \%$, and $101 \%$ at $\mathrm{AA}=0 \mathrm{~g} / \mathrm{L}, 1 \mathrm{~g} / \mathrm{L}$, $2.5 \mathrm{~g} / \mathrm{L}, 5 \mathrm{~g} / \mathrm{L}, 10 \mathrm{~g} / \mathrm{L}$, and $20 \mathrm{~g} / \mathrm{L}$, respectively, which indicated that the usage of AA should be controlled at about $10 \mathrm{~g} / \mathrm{L}$.

3.5. Heating Temperature and Time. Heating temperature was an important factor affecting the accuracy of the PNP determination. In Figure 7(a), all the recovery rates of PNP were more than $110 \%$ at $T<60^{\circ} \mathrm{C}$, while the recovery rates were close to $100 \%$ at $T \geq 60^{\circ} \mathrm{C}$. However, too high a temperature might affect the chemical properties of the organic pollutant, which is not conducive to the determination of the pollutant. Synthetically, $60^{\circ} \mathrm{C}$ was confirmed as the ideal heating temperature in the improved method. Similarly, the heating time of $20 \mathrm{~min}$ is best according to the results shown in Figure 7(b).

3.6. Accuracy and Precision. As we all know, the concentration of PNP varies over a wide range in no matter groundwater or surface water. In order to simulate the complicated PNP contaminated samples as approximately as possible, a batch of PNP samples containing nano- $\mathrm{Fe}(\mathrm{OH})_{3}$ with different known concentrations were prepared and tested. The accuracy and precision were determined according to the method proposed in this paper. Each sample was repeated 12 times to study the accuracy and precision of the proposed method, and the investigation results are shown in Table 4 . Scientifically, the accuracy and relative standard deviation of the method were less than $3 \%$ and $6 \%$, respectively, which could meet the requirements of practical testing.

3.7. Environmental Implication. In this paper, the problem of $\mathrm{Fe}(\mathrm{OH})_{3}$ nanoparticles interfering with the colorimetric test of PNP has been solved successfully, and the proposed method is simple, reliable, and applicable. It is demonstrated that the heating-acidizing method works well in destroying the stable nanocolloids, which results in the elimination of the interference of ENP and accuracy improvement of POP determination. Although it is not a so advanced technique, the UV-Vis spectrophotometer is available in almost all laboratories due its low price and practicability. Therefore, this research could provide new ideas for both environmental workers and laboratory staff who are not equipped with large-scale equipment, and it has more extensive application value.

The reported method had not been used to treat real samples, but got successful applications in our subsequent research of scientific samples. Actually, Fe-based nanomaterials had been demonstrated to be effective catalyst for remediation of groundwater/surface water which were contaminated by PNP or some other organic species. However, the determined concentration of PNP was always inaccurate by spectrophotometry because the interference of $\mathrm{Fe}(\mathrm{OH})_{3}$ nanoparticles which was gradually evolved from the Fe-based nanomaterials. This technical challenge had been perfectly solved by this improved method, and as a methodology study, this work provided a technical guarantee as well for the remediation from other nanoparticles.

Actually, because of the burgeoning nanotechnology, there may be not only Fe-based nanoparticles, but also Ag nanoparticles [45], $\mathrm{Au}$ nanoparticles [46], $\mathrm{TiO}_{2}$ nanoparticles [47], Cu-based nanoparticles [48], etc., in the various samples. It is possible that these engineered nanoparticles interfere with the accuracy of the pollutant testing. In this case, heating-acidification can be used to destroy the stability of the nanoparticles so that a better and more accurate determination can be achieved. 


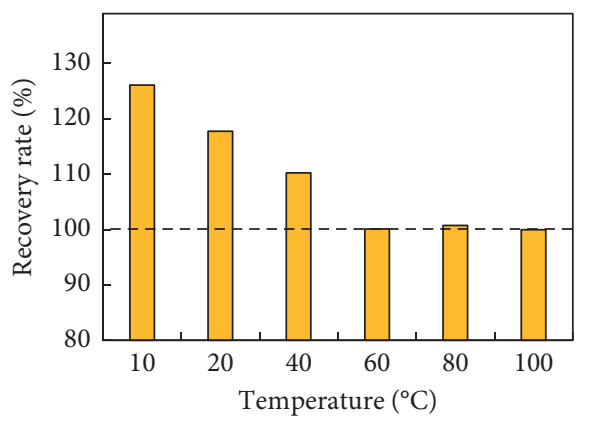

(a)

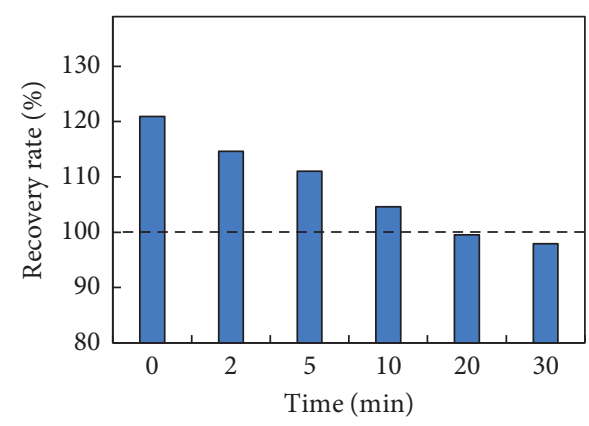

(b)

Figure 7: (a) Optimization of heating temperature. (b) Optimization of heating time.

TABLE 4: The results of accuracy and precision.

\begin{tabular}{|c|c|c|c|c|c|c|}
\hline Serial no. & Preparation sample $(\mathrm{mg} / \mathrm{L})$ & Times & Mean (mg/L) & Accuracy (\%) & $\mathrm{SD}^{1}$ & $\mathrm{RSD}^{2}(\%)$ \\
\hline 1 & 2 & 12 & 2.06 & 2.93 & 0.11 & 5.31 \\
\hline 2 & 4 & 12 & 3.94 & -1.39 & 0.20 & 5.17 \\
\hline 3 & 6 & 12 & 6.05 & 0.85 & 0.22 & 3.61 \\
\hline 4 & 8 & 12 & 8.13 & 1.59 & 0.17 & 2.11 \\
\hline 5 & 10 & 12 & 9.92 & -0.76 & 0.15 & 1.48 \\
\hline 6 & 12 & 12 & 11.94 & -0.47 & 0.09 & 0.75 \\
\hline 7 & 14 & 12 & 14.02 & 0.12 & 0.12 & 0.87 \\
\hline 8 & 16 & 12 & 15.79 & -1.30 & 0.13 & 0.80 \\
\hline 8 & 20 & 12 & 20.23 & 1.15 & 0.49 & 2.44 \\
\hline 10 & 30 & 12 & 30.09 & 0.30 & 0.35 & 1.15 \\
\hline 11 & 40 & 12 & 40.14 & 0.34 & 0.42 & 1.06 \\
\hline 12 & 50 & 12 & 50.70 & 1.40 & 0.48 & 0.94 \\
\hline
\end{tabular}

${ }^{1} \mathrm{SD}$ : standard deviation; ${ }^{2} \mathrm{RSD}$ : relative standard deviation.

To sum up the above arguments, the most important advantage of the proposed method over other spectrophotometric methods is to realize the colorimetric determination of environmental pollutants under the interference of ENPs, which greatly expands application scope of spectrophotometry technology.

\section{Conclusions}

In this paper, methanol was used to quench high-energy free radicals, nano- $\mathrm{Fe}(\mathrm{OH})_{3}$ colloid was destroyed by $\mathrm{HCl}$ at medium temperature, and ascorbic acid was used to mask $\mathrm{FeCl}_{3}$. We successfully established a new, accurate colorimetric method for the determination of PNP in the presence of $\mathrm{Fe}(\mathrm{OH})_{3}$ nanoparticles. The results of batch experiments showed that the most suitable conditions for the colorimetric system were that the dosages of $\mathrm{HCl}$, ascorbic acid, and methanol were $5 \%, 1 \mathrm{~g} / \mathrm{L}$, and $10 \%$, respectively, the temperature of acidizing pretreatment was $60^{\circ} \mathrm{C}$, and the heating time was $20 \mathrm{~min}$. Moreover, it was proven that PNP could be tested simply and effectively, even in high-salinity water samples. Both the accuracy and the precision of the proposed method were good, and they could meet the requirements of actual samples. Scientifically, this work provided new ideas for analysis and testing in the presence of engineered nanoparticles.

\section{Data Availability}

The data used to support the results of this study are included within the article. Any further information is available from the corresponding author upon request.

\section{Conflicts of Interest}

The authors declare that there are no conflicts of interest regarding the publication of this paper.

\section{Authors' Contributions}

Hui Xia and Yuesuo Yang conceived and designed the experiments; Hui Xia performed the experiments, prepared the original draft, and analyzed the data; Wenjing Zhang and Yuesuo Yang contributed with reagents/materials/analysis tools; and Zhijie Yang and Zhenxue Dai were responsible for funding acquisition, review, and editing. All authors have read and agreed to the published version of the manuscript.

\section{Acknowledgments}

This research was funded by the National Major R\&D Program of China (no. 2018YFC1800904), the NSFC 
Projects (nos. 41703125 and 21503191), and the Major R\&D Project of Liaoning Province (no. 2020JH2/10300083).

\section{References}

[1] J. Park and S. Bae, "Formation of Fe nanoparticles on waterwashed coal fly ash for enhanced reduction of p-nitrophenol," Chemosphere, vol. 202, pp. 733-741, 2018.

[2] W. P. da Silva, T. D. Carlos, G. S. Cavallini, and D. H. Pereira, "Peracetic acid: structural elucidation for applications in wastewater treatment," Water Research, vol. 168, Article ID 115143, 2020.

[3] A. Khan, Z.-u. Rehman, A. Khan et al., "Solar-light driven photocatalytic conversion of $\mathrm{p}$-nitrophenol to $\mathrm{p}$-aminophenol on CdS nanosheets and nanorods," Inorganic Chemistry Communications, vol. 79, pp. 99-103, 2017.

[4] N. Xiao, S. G. Liu, S. Mo et al., "Highly selective detection of p-nitrophenol using fluorescence assay based on boron, nitrogen co-doped carbon dots," Talanta, vol. 184, pp. 184-192, 2018.

[5] P.-P. Zhang, Z.-G. Shi, and Y.-Q. Feng, "Determination of phenols in environmental water samples by two-step liquidphase microextraction coupled with high performance liquid chromatography," Talanta, vol. 85, no. 5, pp. 2581-2586, 2011.

[6] S.-P. Sun and A. T. Lemley, "p-nitrophenol degradation by a heterogeneous fenton-like reaction on nano-magnetite: process optimization, kinetics, and degradation pathways," Journal of Molecular Catalysis A: Chemical, vol. 349, no. 1-2, pp. 71-79, 2011.

[7] J. I. Cacho, N. Campillo, P. Viñas, and M. HernándezCórdoba, "Dispersive liquid-liquid microextraction for the determination of nitrophenols in soils by microvial insert large volume injection-gas chromatography-mass spectrometry," Journal of Chromatography A, vol. 1456, pp. 27-33, 2016.

[8] J. A. Padilla-Sánchez, P. Plaza-Bolaños, R. Romero-González, A. Garrido-Frenich, and J. L. Martínez Vidal, "Application of a quick, easy, cheap, effective, rugged and safe-based method for the simultaneous extraction of chlorophenols, alkylphenols, nitrophenols and cresols in agricultural soils, analyzed by using gas chromatography-triple quadrupole-mass spectrometry/mass spectrometry," Journal of Chromatography A, vol. 1217, no. 36, pp. 5724-5731, 2010.

[9] J. Zhang, S. Cui, Y. Ding, X. Yang, K. Guo, and J.-T. Zhao, "Two-dimensional mesoporous $\mathrm{ZnCo}_{2} \mathrm{O}_{4}$ nanosheets as a novel electrocatalyst for detection of o-nitrophenol and p-nitrophenol," Biosensors and Bioelectronics, vol. 112, pp. 177-185, 2018.

[10] T. Zhang, Q. Lang, D. Yang et al., "Simultaneous voltammetric determination of nitrophenol isomers at ordered mesoporous carbon modified electrode," Electrochimica Acta, vol. 106, pp. 127-134, 2013.

[11] G. Li, T. V. Nykaza, J. C. Cooper, A. Ramirez, M. R. Luzung, and A. T. Radosevich, "An improved PIII/PV=O-catalyzed reductive $\mathrm{C}-\mathrm{N}$ coupling of nitroaromatics and boronic acids by mechanistic differentiation of rate-and product-determining steps," Journal of the American Chemical Society, vol. 142, no. 14, pp. 6786-6799, 2020.

[12] M. M. Khin, A. S. Nair, V. J. Babu, R. Murugan, and S. Ramakrishna, "A review on nanomaterials for environmental remediation," Energy \& Environmental Science, vol. 5, no. 8, p. 8075, 2012.
[13] F. Lu and D. Astruc, "Nanomaterials for removal of toxic elements from water," Coordination Chemistry Reviews, vol. 356, pp. 147-164, 2018.

[14] J. Wang, K. Chang, Z. Sun et al., "A Combined experimental and theoretical study of the accelerated hydrogen evolution kinetics over wide $\mathrm{pH}$ range on porous transition metal doped tungsten phosphide electrocatalysts," Applied Catalysis B: Environmental, vol. 251, pp. 162-167, 2019.

[15] B. Bayatsarmadi, Y. Zheng, A. Vasileff et al., "Recent advances in atomic metal doping of carbon-based nanomaterials for energy conversion," Small, vol. 13, no. 21, 2017.

[16] A. P. Blum, J. K. Kammeyer, A. M. Rush, C. E. Callmann, M. E. Hahn, and N. C. Gianneschi, "Stimuli-responsive nanomaterials for biomedical applications," Journal of the American Chemical Society, vol. 137, no. 6, pp. 2140-2154, 2015.

[17] C. Contado, "Nanomaterials in consumer products: a challenging analytical problem," Frontiers in Chemistry, vol. 3, p. $48,2015$.

[18] M. E. Vance, T. Kuiken, E. P. Vejerano et al., "Nanotechnology in the real world: redeveloping the nanomaterial consumer products inventory," Beilstein Journal of Nanotechnology, vol. 6, pp. 1769-1780, 2015.

[19] A. Jain, S. Ranjan, N. Dasgupta, and C. Ramalingam, "Nanomaterials in food and agriculture: an overview on their safety concerns and regulatory issues," Critical Reviews in Food Science and Nutrition, vol. 58, no. 2, pp. 297-317, 2018.

[20] R. Xiao, L. Gao, Z. Wei et al., "Mechanistic insight into degradation of endocrine disrupting chemical by hydroxyl radical: an experimental and theoretical approach," Environmental Pollution, vol. 231, no. 2, pp. 1446-1452, 2017.

[21] X. Yang, Y. Zhang, F. Chen, and Y Yang, "Interplay of natural organic matter with flow rate and particle size on colloid transport: experimentation, visualization, and modeling," Environmental Science \& Technology, vol. 49, no. 22, pp. 13385-13393, 2015.

[22] M. Adeel, X. Song, Y. Wang, D. Francis, and Y. Yang, "Environmental impact of estrogens on human, animal and plant life: a critical review," Environment International, vol. 99, pp. 107-119, 2017.

[23] X. Song, Y. Wen, Y. Wang, M. Adeel, and Y. Yang, "Environmental risk assessment of the emerging EDCs contaminants from rural soil and aqueous sources: analytical and modelling approaches," Chemosphere, vol. 198, pp. 546-555, 2018.

[24] F. Part, N. Berge, P. Baran et al., "A review of the fate of engineered nanomaterials in municipal solid waste streams," Waste Management, vol. 75, pp. 427-449, 2018.

[25] R. K. Ibrahim, M. Hayyan, M. A. AlSaadi, A. Hayyan, and S. Ibrahim, "Environmental application of nanotechnology: air, soil, and water," Environmental Science and Pollution Research, vol. 23, no. 14, pp. 13754-13788, 2016.

[26] T. Liu, K. Yin, C. Liu et al., "The role of reactive oxygen species and carbonate radical in oxcarbazepine degradation via UV, $\mathrm{UV} / \mathrm{H}_{2} \mathrm{O}_{2}$ : kinetics, mechanisms and toxicity evaluation," Water Research, vol. 147, pp. 204-213, 2018.

[27] Q. Chen, J. Zheng, J. Xu, Z. Dang, and L. Zhang, "Insights into sulfamethazine adsorption interfacial interaction mechanism on mesoporous cellulose biochar: coupling DFT/FOT simulations with experiments," Chemical Engineering Journal, vol. 356, pp. 341-349, 2019.

[28] S. Luo, L. Gao, Z. Wei et al., "Kinetic and mechanistic aspects of hydroxyl radical-mediated degradation of naproxen and 
reaction intermediates," Water Research, vol. 137, pp. 233241, 2018.

[29] K. Lv, X. Guo, X. Wu et al., "Photocatalytic selective oxidation of phenol to produce dihydroxybenzenes in a $\mathrm{TiO}_{2} / \mathrm{UV}$ system: hydroxyl radical versus hole," Applied Catalysis B: Environmental, vol. 199, pp. 405-411, 2016.

[30] W. Liu, Y. Li, F. Liu, W. Jiang, D. Zhang, and J. Liang, "WITHDRAWN: visible-light-driven photocatalytic degradation of diclofenac by carbon quantum dots modified porous g- $\mathrm{C}_{3} \mathrm{~N}_{4}$ : mechanisms, degradation pathway and DFT calculation," Water Research, vol. 150, pp. 431-441, 2019.

[31] H. Li, X. Miao, J. Zhang et al., "DFT studies on the reaction mechanism and kinetics of dibutyl phthalate initiated by hydroxyl and sulfate radicals: prediction of the most reactive sites," Chemical Engineering Journal, vol. 381, p. 122680, 2020.

[32] B. Liu, Z. Liu, P. Yu et al., "Enhanced removal of tris(2chloroethyl) phosphate using a resin-based nanocomposite hydrated iron oxide through a Fenton-like process: capacity evaluation and pathways," Water Research, vol. 175, p. 115655, 2020.

[33] X. Jin, J. Zhuang, Z. Zhang, H. Guo, and J. Tan, "Hydrothermal synthesis of hydroxyapatite nanorods in the presence of sodium citrate and its aqueous colloidal stability evaluation in neutral $\mathrm{pH}$," Journal of Colloid and Interface Science, vol. 443, pp. 125-130, 2015.

[34] X. Li, D. Zhu, and X. Wang, "Evaluation on dispersion behavior of the aqueous copper nano-suspensions," Journal of Colloid and Interface Science, vol. 310, no. 2, pp. 456-463, 2007.

[35] G. F. Zhu, Y. H. Su, and Q. Feng, "The hydrochemical characteristics and evolution of groundwater and surface water in the Heihe River Basin, northwest China," Hydrogeology Journal, vol. 16, no. 1, pp. 167-182, 2008.

[36] J. Li, F. Li, Q. Liu, and Y. Zhang, "Trace metal in surface water and groundwater and its transfer in a Yellow River alluvial fan: evidence from isotopes and hydrochemistry," Science of the Total Environment, vol. 472, pp. 979-988, 2014.

[37] M. Cheng, G. Zeng, D. Huang et al., "Hydroxyl radicals based advanced oxidation processes (AOPs) for remediation of soils contaminated with organic compounds: a review," Chemical Engineering Journal, vol. 284, pp. 582-598, 2016.

[38] A. Babuponnusami and K. Muthukumar, "A review on Fenton and improvements to the Fenton process for wastewater treatment," Journal of Environmental Chemical Engineering, vol. 2, no. 1, pp. 557-572, 2014.

[39] Y. J. Wen, Y. S. Yang, H. J. Ren et al., "Chemical-biological hybrid reactive zones and their impact on biodiversity of remediation of the nitrobenzene and aniline contaminated groundwater," Chemical Engineering Journal, vol. 280, pp. 233-240, 2015.

[40] Y. Ma, F. Chen, Q. Yang et al., "Sulfate radical induced degradation of Methyl Violet azo dye with CuFe layered doubled hydroxide as heterogeneous photoactivator of persulfate," Journal of Environmental Management, vol. 227, pp. 406-414, 2018.

[41] J. Zhao, Y. Zhang, X. Quan, and S. Chen, "Enhanced oxidation of 4-chlorophenol using sulfate radicals generated from zerovalent iron and peroxydisulfate at ambient temperature," Separation and Purification Technology, vol. 71, no. 3, pp. 302-307, 2010.

[42] X. Guo, G. Yue, J. Huang, C. Liu, Q. Zeng, and L. Wang, "Label-free simultaneous analysis of $\mathrm{Fe}(\mathrm{III})$ and ascorbic acid using fluorescence switching of ultrathin graphitic carbon nitride nanosheets," ACS Applied Materials \& Interfaces, vol. 10, no. 31, pp. 26118-26127, 2018.

[43] Y. Zhao and D. G. Truhlar, "A new local density functional for main-group thermochemistry, transition metal bonding, thermochemical kinetics, and noncovalent interactions," The Journal of Chemical Physics, vol. 125, no. 19, Article ID 194101, 2006.

[44] J. D. Dill and J. A. Pople, "Self-consistent molecular orbital methods. XV. extended Gaussian-type basis sets for lithium, beryllium, and boron," The Journal of Chemical Physics, vol. 62 , no. 7, pp. 2921-2923, 1975.

[45] X. Zhang, C. Zhang, A. Abas et al., "Ag nanoparticles enhanced vertically-aligned $\mathrm{CuO}$ nanowire arrays grown on $\mathrm{Cu}$ foam for stable hybrid supercapacitors with high energy density," Electrochimica Acta, vol. 296, pp. 535-544, 2019.

[46] L. Kong, Y. Guo, X. Wang et al., "Double-walled hierarchical porous silica nanotubes loaded Au nanoparticles in the interlayer as a high-performance catalyst," Nanotechnology, vol. 31, no. 1, Article ID 015701, 2020.

[47] E. Morelli, E. Gabellieri, A. Bonomini, D. Tognotti, G. Grassi, and I. Corsi, " $\mathrm{TiO}_{2}$ nanoparticles in seawater: aggregation and interactions with the green alga Dunaliella tertiolecta," Ecotoxicology and Environmental Safety, vol. 148, pp. 184-193, 2018.

[48] M. B. Gawande, A. Goswami, F.-X. Felpin et al., " $\mathrm{Cu}$ and $\mathrm{Cu}$ based nanoparticles: synthesis and applications in catalysis," Chemical Reviews, vol. 116, no. 6, pp. 3722-3811, 2016. 